International Journal of Applied Linguistics \& English Literature

ISSN 2200-3592 (Print), ISSN 2200-3452 (Online)

Vol. 1 No. 7; November 2012 [Special Issue on Applied Linguistics]

\title{
A Comparative Study of the Rhetorical Moves in Abstracts of Published Research Articles and Students' Term Papers in the Field of Computer and Communication Systems Engineering
}

\author{
Lam Yik San \\ Faculty of Modern Languages and Communication \\ Universiti Putra Malaysia \\ 43400 UPM Serdang, Selangor \\ E-mail: lamyiksan@yahoo.com \\ Helen Tan \\ Faculty of Modern Languages and Communication \\ Universiti Putra Malaysia \\ 43400 UPM Serdang, Selangor \\ E-mail: helen@fbmk.upm.edu.my
}

Received: 20-10- 2012

doi:10.7575/ijalel.v.1n.7p.40
Accepted: 22-11- 2012

Published: 25-11- 2012

URL: http://dx.doi.org/10.7575/ijalel.v.1n.7p.40

\begin{abstract}
This study seeks to compare and contrast the rhetorical moves in abstracts of students' term papers and published articles in the field of Computer and Communications Systems Engineering. The reason is to identify to what extend the rhetorical moves used in the abstracts of students' term papers approximate to the published articles. Using Santos' (1996) five move pattern as the model of analysis, the data indicated that both the abstracts in the students' term papers and the published articles did use some of the rhetorical moves. However, the pattern of use did vary among them. Furthermore, the study also revealed that abstracts with a complete five moves presented a more comprehensive overview of the content of the study when compared with abstracts with limited moves. These findings could heighten the awareness of the student writers as to how abstract writing should be structured and it could also increase their sophistication in the crafting of an effective abstract. Finally, the data could also form as an informed input for both writing instructors and program designers to incorporate the learning of the rhetorical moves in abstract writing instructions.
\end{abstract}

Keywords: Expert Writers, Novice Writers, L2 Writers, Rhetorical moves, Abstract Writing

\section{Introduction}

An abstract is a brief, comprehensive summary of the content of an article or research proposal (Fain, 1998).It allows the readers to view the contents without having to read the complete article. According to Van Bonn and Swales (2007), the common text length of an abstract is usually between 100-250 words and it includes the main features and findings of the study. Even though short, abstract writing like other types of academic writing (thesis, technical report, research articles, to name a few) is a genre on its own. In other words, abstract writing has an accepted formal structure that is known and accepted by the discourse community.

This formal structure or organization in abstract writing is realized in the form of the rhetorical moves in abstract writing. Such a notion was first mooted by Swales $(1981,1990)$ who investigated the introduction of Research Articles (RA) and found them to contain a regular pattern of 'moves' and 'steps'. Swales $(1981,1990)$ posits that for a writer to write the introduction section of a research article succinctly, he has to write commencing with Move 1 which is establishing a territory. Within Move 1, the writer has to claim centrality to his work, making topic generalization and reviewing previous research (see Table 1). Next, he has to establish a niche (Move 2) where the writer has to indicate the gap of his research and finally concluding with Move 3 which is occupying a niche where the writer announces the purpose of his study. 
International Journal of Applied Linguistics \& English Literature

ISSN 2200-3592 (Print), ISSN 2200-3452 (Online)

Vol. 1 No. 7; November 2012 [Special Issue on Applied Linguistics]

Table 1. Swales Identification of Moves and Steps in the Introductory Section of a Research Article

\begin{tabular}{ll} 
Move 1 & Establishing a territory \\
& Step 1: Claiming centrality \\
& Step 2: Making topic generalization(s) \\
& Step 3: Reviewing items of previous research \\
Move 2 & Establishing a niche (BOLD) \\
& Step 1: Indicating a gap \\
Move 3 & Occupying the niche (BOLD) \\
& Step 1: Announcing present research \\
\hline
\end{tabular}

Swales' $(1981,1990)$ idea on moves in writing introduction in research articles has motivated many researchers to look for regular patterns in other types of academic writing. One such area that is of interest to researchers is the move-pattern in abstract writing. Swales' $(1981,1990)$ model has been widely used in analyzing introductions in various English academic genres such as in business writing (Bhatia, 1993; Hiranburana, 1996; Chakorn, 2002). Other studies which were also influenced by Swales' work are those by Graetz (1985) and Salvager-Meyer (1990). Graetz (1985) examines rhetorical moves in RA and found them to have the following pattern: Problem Method - Results - Conclusion. On the other hand, Salvager-Meyer (1990) investigated the moves in the abstracts of research article and found that there were six moves. They are Statement - Purpose Corpus/Method - Results - Conclusion - Recommendation.

It has also been found that besides the regular move pattern, variation in the rhetorical move structures is also observed in abstract writing. Huckin (2001), for example, found that the abstracts of medical fields often have the exclusion of stating the purpose as a move. Meanwhile, Kanokslapatham (2007) found that the occurrence of Move 3, Step 5: Announcing principal outcome in biochemistry (52 abstracts) occurs twice as frequently as in the microbiology (26 abstracts). As noted by Bhatia (1993), differences of style and rhetorical structures exist in the macro-organization of writing and they could be due to different genres serving different communicative purposes.

As the literature on abstract writing abound, the rhetorical moves in abstract writing constantly undergo further examination and development. Santos's (1996) five-move model is an example. Noting the inadequacy of Swales' (1980) CARS model, he proposes that the organization of abstract writing could be characterized based on moves and each move has a clear function. (see Table 2).

Table 2. Santos' (1996) framework for abstract analysis

\begin{tabular}{|c|c|c|}
\hline Moves & Function/Description & Question asked \\
\hline $\begin{array}{l}\text { Move 1: Situating the research } \\
<\text { STR }>\end{array}$ & $\begin{array}{l}\text { Setting the scene for the current } \\
\text { research(topic generalization) }\end{array}$ & $\begin{array}{l}\text { What has been known about } \\
\text { the field/topic of research? }\end{array}$ \\
\hline $\begin{array}{l}\text { Move 2: Presenting the research } \\
<\text { PTR }>\end{array}$ & $\begin{array}{l}\text { Stating the purpose of the study, research } \\
\text { questions and/or hypotheses }\end{array}$ & What is the study about? \\
\hline $\begin{array}{l}\text { Move 3: Describing the } \\
\text { methodology }<\text { DTM }>\end{array}$ & $\begin{array}{l}\text { Describing the materials, subjects, } \\
\text { variables, procedures }\end{array}$ & How was the research done? \\
\hline $\begin{array}{l}\text { Move 4: Summarizing the } \\
\text { findings }<\mathrm{STF}>\end{array}$ & Reporting the main findings of the study & What did the researcher find? \\
\hline $\begin{array}{l}\text { Move 5: Discussing the research } \\
\text { <DTR> }\end{array}$ & $\begin{array}{l}\text { Interpreting the results/findings and/or } \\
\text { giving recommendations, } \\
\text { implications/applications of study }\end{array}$ & $\begin{array}{l}\text { What do the results mean? } \\
\text { So what? }\end{array}$ \\
\hline
\end{tabular}


International Journal of Applied Linguistics \& English Literature

ISSN 2200-3592 (Print), ISSN 2200-3452 (Online)

Vol. 1 No. 7; November 2012 [Special Issue on Applied Linguistics]

As seen in Table 2, Santos (1996) believes that a clear comprehensive abstract should have 5 moves. It commences with Move 1, Situating the research (STR) in which the setting for the current research is discussed followed by Move 2, Presenting the research (PTR). In Move 2, the purpose of the study, research questions or hypotheses are presented. The next move is Move 3 which is Describing the methodology (DTM). It describes the materials, subjects, variables and procedures used in a study. This move is then followed by the findings of the study in Move 4 which is known as Summarizing the findings (STF). In this move, the writers report the main findings of the study in brief. Finally, the framework ends with Move 5, Discussing the research (DTR) where the results or findings are found, where recommendations, implications or applications are discussed.

Using his five-move pattern framework, he analyses 93 selected abstracts in the discipline of Applied Linguistics. He found that almost all of the abstracts used Move 2, Move 3 and Move $4.80 \%$ of the abstracts have Move 5 while the least used move was Move 1 which only saw $43 \%$ of usage.

Like Swales (1980), Santos' (1996) framework of abstract analysis has also greatly influenced the works of researchers that came after him. One such work was by Pho (2008). Using Santos' model, he conducted a study on abstract writing in applied linguistics and educational technology. In his study, he found that all of the abstracts in his studies contained Move 2 to Move 5 . Move 5 was recorded as $80 \%$ of occurrence and Move 1, on the other hand, appears as the least used move with only 43\%. As seen in the findings, Santos' (1996) and Pho's (2008) findings revealed a similar pattern which suggested that Move 2, Move 3 and Move 4 are obligatory moves whereas Move 1 is seen as the optional move in abstract writing. However, in Santos' study (1996) Move 5 appears to be a less obligatory move with only $53 \%$ of occurrence.

Although research into abstract writing have all pointed to the importance of a regular pattern in the organization of abstract writing, such convention in writing maybe unknown to L2 writers, particularly to L2 beginner writers. To compound the problems, L2 writers also have problems with the syntax, morphology and semantics of English. This has been documented in several studies. Ventola (1994) found that German scholars had difficulties in producing English-language abstracts in their own fields. Additionally, Johns (1992) also showed how Brazilian scholars struggle to write their abstract writing in English where it was found that that they tend to translate Portuguese structures into English inappropriately. Birch (1996), in his study also highlighted that French scholars frequently make lexico-grammatical errors when writing in English.

Towards this end, this study seeks to examine the rhetorical moves in the abstract writing of students' term papers and that of published articles. Students' writings are often unsophisticated and therefore can be termed as beginner writers' writings. On the other hand, published articles which would have gone through some editorial process by the discourse community could be considered as the benchmark the beginner writers could aspire to. As a result of these rationales, the following research questions were framed to guide the study.

1. What are the frequency of use of the rhetorical moves in the abstracts of both the students' term papers and published articles in the field of Computer and Communications Systems Engineering?

2. How are the moves in the abstracts written in the students' term papers different from the ones in the published articles?

3. How does the use of the rhetorical moves affect the overall comprehensibility of the content of the study?

\section{Methodology}

To realize the objectives of the study, a quantitative analysis was adopted where the frequency of occurrences (in percentages) of the moves in the abstracts of student writers and writers of published articles were tabulated. The selection of the samples of abstracts of students' term papers and writers of published articles in the field of Computer and Communication Systems Engineering and the instrument used in the study are discussed below.

\subsection{The abstracts of published articles}

A total of thirty abstracts from three recognized published journals in the area of Computer and Communication Systems Engineering were chosen randomly from the year 2005-2012. Seven abstracts were selected from the Journal on Decision Support Systems, fifteen from the Journal on Computer Communications, and eight from the International Journal of Computer Vision (see Appendix 1). These three journals were chosen based on information gathered from an expert informant. These journals are high impact factor journals and therefore are from reputed journals in the field of Computer and Communication Systems Engineering. As this being the case, the writers from this selection of abstracts will henceforth be known as expert writers' abstracts. 
International Journal of Applied Linguistics \& English Literature

ISSN 2200-3592 (Print), ISSN 2200-3452 (Online)

Vol. 1 No. 7; November 2012 [Special Issue on Applied Linguistics]

\subsection{The abstracts of students' term papers}

A total of 30 final year project papers of the Computer and Communication Systems Engineering undergraduates in a Malaysian university from the year 2009 - 2010 were compiled. Their selection was mainly based on convenience sampling as the researcher could only compile what was given. To distinguish the expert writers' abstracts with the abstract writing of the students' term papers, the writers of this collection of abstracts will henceforth be known as novice writers' abstract. This is because abstracts of students' term papers would normally not go through any blind review in the editorial process as compared with the expert writers' abstracts. Therefore, writers of this group of abstracts may not be that adept in the skill of academic writing.

\subsection{Instrument}

The instrument used as the analytical framework was that of Santos's (1996) five-move-pattern. The reason for adopting Santos' model is that it is comprehensive and clear to use as a framework of analysis as he has each move clearly explained (see table 2 above). For each move, he provides the function and some leading questions that would help writers to identify the moves more succinctly. The usefulness of Santos' (1996) model as a framework for analysis has also been adopted by several researchers such as Bhatia (1993), Graetz (1985) and Pho (2007).

\subsection{Analysis Procedures}

The analysis of abstracts in this study involved several stages. The initial stage in analysing an abstract was the division of the content of the abstract into individual sentences. To maintain objectivity in the analysis, the identifications of the moves in the abstracts were done by two raters and the researcher. If there were discrepancy in distinguishing a particular move in a sentence, both the raters and the researcher would discuss and agree on a common solution. An example of how an abstract was coded is shown in Table 3.

Table 3. Analysis of the Move Structure of an Abstract
Sentence
Text (719)
Moves

\begin{tabular}{|c|c|c|}
\hline S1 & $\begin{array}{l}\text { Passive RFID can be read only at a very short distances in order of } \\
\text { several meter. }\end{array}$ & $\begin{array}{l}\text { Move 1: } \\
\text { STR }\end{array}$ \\
\hline $\mathbf{S 2}$ & This greatly limits its usefulness for certain applications. & $\begin{array}{c}\text { Move 1: } \\
\text { STR }\end{array}$ \\
\hline S3 & $\begin{array}{l}\text { Passive RFID tags do not have any internal source of energy, such as } \\
\text { a battery; instead it gets all the energy needed for functioning from } \\
\text { the electromagnetic radiation emitted by the reader. }\end{array}$ & $\begin{array}{l}\text { Move 1: } \\
\text { STR }\end{array}$ \\
\hline S4 & $\begin{array}{l}\text { The objectives for this project to survey the existing long distance } \\
\text { passive RFID tag, evaluate existing solution of RFID tag and analyses } \\
\text { RF properly of the long distant RFID tag. }\end{array}$ & $\begin{array}{l}\text { Move 2: } \\
\text { PTR }\end{array}$ \\
\hline S5 & $\begin{array}{l}\text { The reader use in this study is Class I Generation } 2 . \text { The study overall } \\
\text { focusing on power source and distance. }\end{array}$ & $\begin{array}{c}\text { Move 3: } \\
\text { DTM }\end{array}$ \\
\hline S6 & $\begin{array}{l}\text { From the results, Motorola reader able to read the tag more than } 8 \mathrm{~m} \\
\text { compared with Samsung reader only measure until } 5 \mathrm{~m} .\end{array}$ & $\begin{array}{l}\text { Move 4: } \\
\text { STF }\end{array}$ \\
\hline S7 & The higher of frequency the long of distance can read by the reader. & $\begin{array}{l}\text { Move 5: } \\
\text { DTR }\end{array}$ \\
\hline S8 & Conclusion, Motorola reader is better than Samsung reader. & $\begin{array}{l}\text { Move 5: } \\
\text { DTR }\end{array}$ \\
\hline
\end{tabular}




\section{International Journal of Applied Linguistics \& English Literature}

ISSN 2200-3592 (Print), ISSN 2200-3452 (Online)

Vol. 1 No. 7; November 2012 [Special Issue on Applied Linguistics]

As seen in Table 2, abstract 719 has eight sentences (S1, S2...S8). The move for each sentence was then identified. They were identified based on Swales' (1990:131-132) bottom-up and top-down approaches. The bottom-up approach is where the identifications of the moves in the abstracts are distinguished clearly by the linguistic realization of the moves. The examples below show the linguistic realization (in bold) that determined the moves in the abstracts.

1. The objectives for this project to survey the existing long distance passive RFID tag, evaluate existing solution of RFID tag and analyses RF properly of the long distant RFID tag. (Move 2: PTR) (Text 719)

2. We conclude that both static and dynamic channel allocation strategies have advantages and disadvantages, and the design of channel allocation algorithms strongly depends on the interference model and the assumption of network traffic.(Move 4: STF) (Computer Communications 121)

As seen in the examples above, the use of lexical features (in bold) which explicitly state the types of moves used. The noun phrase, "The objectives for this project to survey...." distinguished clearly that the move used is Move 2 and "We conclude that both static...." evidently shows that this sentence belongs to Move 4. In the absence of a clear linguistic signal to identify the moves, the top-down approach was used. This approach distinguishes moves based on the content of the abstracts. In other words, the moves were distinguished based on the meaningful reading of a sentence itself or a few sentences to define which move it belongs to. This is shown in the examples below,

3. The fundamental idea of the project is to create a sign language glove to detect and interpret the hand gesture of American Sign Language (ASL). (Move2: PTR) (Text 733)

4. Furthermore, the creation of the diffusion animation is in a instant and also requires significantly lower computational cost compared to any recent methods. (Move 3: DTM) (Text 746)

The verb phrases (is to create, to detect and interpret) with the presence of the noun phrase (the fundamental idea) in example 3, distinguished the move as Move 2. Meanwhile, the structures of the sentence in example 4 with the verb (requires) after the noun phrase (the creation of the diffusion animation), distinguished the sentence as Move 3 .

As stated by Santos (1996) and Holmes (1997), solution to the identification moves of 'fuzzy' sentences in abstracts was dependent on each sentence as the basic unit for the analysis. However, Mitzuta et al. (2004) claimed that segments of text smaller than a clause in a unit should not be counted as 'moves'. However, given the fact that abstracts are condensed texts, and that there has been evidence of a move embedded in another move in abstracts (see Pho (2008) and Santos (1996), the exclusion of phrases as a move does not seem to be realistic. Thus, for the analysis of the abstracts in this study, a move can be realised by structures ranging from a word, a phrase or even several sentences. This is shown in examples 1 and 2.

Example 1

\begin{tabular}{ccc}
\hline Sentence & \multicolumn{1}{c}{ Text: Computer Communications 124 } & Moves \\
\hline S4 & The new computationally efficient LC is used in turbo equalization and & Move 3: \\
& & DTM \\
& is shown to have equivalent or better performance than the conventional & Move 4: \\
& LC in terms of BER & STF \\
\hline
\end{tabular}

DTM: Describing the Methodology, STF: Situating the Findings 
International Journal of Applied Linguistics \& English Literature

ISSN 2200-3592 (Print), ISSN 2200-3452 (Online)

Vol. 1 No. 7; November 2012 [Special Issue on Applied Linguistics]

Example 2

\begin{tabular}{clc}
\hline Sentence & Text: International Journal of Computer Vision 137 & Moves \\
\hline S3 & Many factors can affect the performance of an iris recognition system, & Move 1: \\
& $\begin{array}{l}\text { STR } \\
\text { and in this study the authors report an experimental investigation of the } \\
\text { interrelationship between some characteristics which are particularly } \\
\text { relevant in understanding how to manage the practical effects of ageing } \\
\text { with respect to this modality. }\end{array}$ & Move 2: \\
\hline
\end{tabular}

STR: Situating the Research, PTR: Presenting the Research

Examples 1 and 2 showed that there was a need to separate the sentence structures into two smaller units due to the different moves used. The sentence in Example 1 has two different moves, Move 3 and Move 4 and the sentence in Example 2 has Move 1 and Move 2. To determine if a move is obligatory, there should be an $80 \%$ of the move occurrence as suggested by Santos (1996) and Pho (2008). Moves which occur below $80 \%$ would be regarded as optional. Besides identifying the move structures, there was also a need to take into consideration the text length of each of the abstract. In this study, the minimum words use in the abstracts was 64 words and with a maximum of 320 words. The decision was motivated by the assumption that text length might affect the number of moves used in an abstract.

To conclude, rigor in methodology in any research is essential to yield an objective finding. Therefore, with Santos' (1996) comprehensive model, it was hoped that results teased from the analysis of the abstracts written by the student writers and writers of the published articles would in some way be informative and insightful on how beginner writers and accomplished writers write.

\section{Results and Discussion}

The frequency of use of the rhetorical moves in the abstracts of expert and novice writers is captured in Figure 1.

Figure 1. The occurrence of rhetorical moves in the expert and the novice writers' abstracts

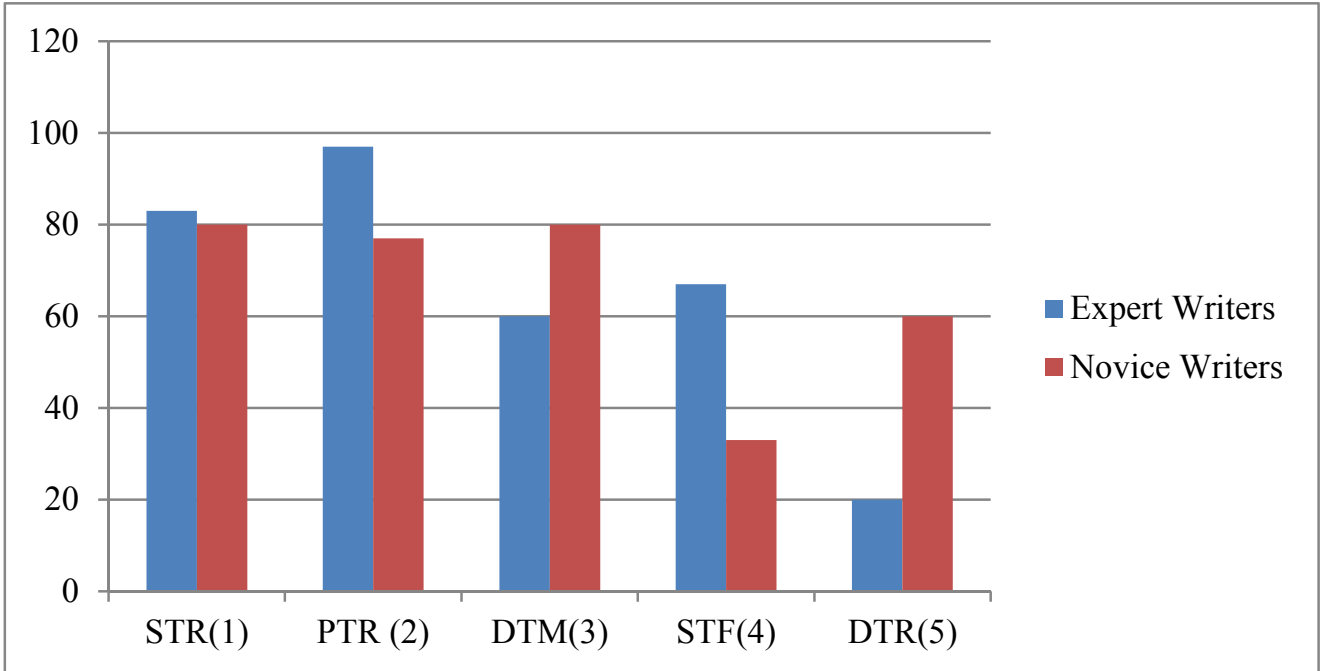

STR: Situating the Research, PTR: Presenting the Research, DTM: Describing the Methodology,

STF: Summarizing the Findings, DTR: Discussing the Research.

Figure 1 above indicated that the expert writers had the highest frequency of move for Move 2 (97\%) followed by Move $1(83 \%)$ respectively. In contrast, Move 5 had the lowest frequency of use $(20 \%)$ followed by Move 3 $(59 \%)$ and Move 4 (67\%). As for the novice writers, Move 1 and Move 3 recorded the highest frequency of use 


\section{International Journal of Applied Linguistics \& English Literature}

ISSN 2200-3592 (Print), ISSN 2200-3452 (Online)

Vol. 1 No. 7; November 2012 [Special Issue on Applied Linguistics]

and with similar frequency of occurrences $(80 \%)$. The next highest frequency of use was Move $2(77 \%)$ followed by Move $5(60 \%)$. In contrast, Move 4 recorded the least frequency of use with a percentage of only $33 \%$.

From these results, it could be concluded that Move 1 and Move 2 were obligatory moves in the abstracts of the expert writers while the other three moves (Move 3, 4 and 5) were seen as optional. In the novice writers' abstracts, however, Move 1 was found to be an obligatory move and the second obligatory move was Move 3 and not Move 2 as found in the expert writers' abstracts. In fact, Move 2 was found to be an optional move. Although the abstracts in both groups of writers registered Move 4 and 5 as optional moves, their frequency of occurrences were quite different. While the expert writers had very low frequency of use for Move $5(20 \%)$, the novice writers' lowest frequency of use was Move 4.

These results indicated that the pattern of use of the rhetorical moves in the novice writers' abstracts did not fully mirror the pattern of use of the rhetorical moves in the expert writers' abstracts. While the expert writers viewed situating the research and presenting the research as important moves in abstract writing, the novice writers perceived describing the methodology as more important than presenting the research.

Besides the difference in the frequency use of the rhetorical moves in the abstracts of both groups of writers, it was noted that the text length in the abstracts were also varied. The text length ranged from 64 words to 320 words. Within this varied text length, it was found that some abstracts used all the five moves while in some, some rhetorical moves were omitted (see Table 4).

Table 4.The number of moves used of the expert and novice writers' abstracts based on the text length.

\begin{tabular}{|c|c|c|c|c|c|c|c|c|c|c|c|c|}
\hline \multirow{3}{*}{$\begin{array}{c}\text { Text } \\
\text { Length } \\
\text { (words) }\end{array}$} & \multicolumn{12}{|c|}{ Number of Rhetorical Moves Used by Expert and Novice Writers } \\
\hline & \multicolumn{2}{|c|}{1} & \multicolumn{2}{|c|}{2} & \multicolumn{2}{|c|}{3} & \multicolumn{2}{|c|}{4} & \multicolumn{2}{|c|}{5} & \multicolumn{2}{|c|}{$\begin{array}{c}\text { TOTAL } \\
\text { ABSTRACTS }\end{array}$} \\
\hline & Nov & Exp & Nov & Exp & Nov & Exp & Nov & Exp & Nov & Exp & Nov & Exp \\
\hline $64-99$ & 0 & 0 & 1 & 5 & 0 & 3 & 0 & 1 & 0 & 0 & 1 & 9 \\
\hline $100-152$ & 0 & 0 & 0 & 2 & 4 & 6 & 1 & 5 & 1 & 2 & 6 & 15 \\
\hline $153-252$ & 1 & 0 & 1 & 0 & 9 & 1 & 4 & 5 & 3 & 0 & 18 & 6 \\
\hline $252-320$ & 0 & 0 & 0 & 0 & 3 & 0 & 2 & 0 & 0 & 0 & 5 & 0 \\
\hline TOTAL & 1 & 0 & 2 & 7 & 16 & 10 & 7 & 11 & 4 & 2 & 30 & 30 \\
\hline
\end{tabular}

Key: Nov: Novice Writers

Exp: Expert Writers

In terms of text length, most expert writers (15 abstracts) wrote a text length of 100-152 words. On the other hand, 18 novice writers'was found to be within the text length of 153-252 words. For the text length of 252-320 words, there was no abstract found from the expert writers. However, five abstracts were found to be from the novice writers. As for the text length of 64-99 words, 9 expert writers' abstract were found as compared with the novice writers where only one abstract was found.

Within these varied text lengths, the majority of the abstracts were found to contain 3 to 4 moves. As found in Table 4 above, a total of 16 novice writers' and 10 expert writers' abstracts had 3 moves while 7 novice writers'and 11 expert writers' abstracts had 4 moves. Surprisingly, only a marginal number of them wrote using all the five moves. Only 4 novice writers' and 2 expert writers' abstracts were found to have all the 5 moves. Writing the abstracts with only one move was found in one novice writer's abstract. However, none of the expert writers wrote their abstracts with only one move. The sample of the one move abstract written by a novice writer is shown in Example 3. 
International Journal of Applied Linguistics \& English Literature

ISSN 2200-3592 (Print), ISSN 2200-3452 (Online)

Vol. 1 No. 7; November 2012 [Special Issue on Applied Linguistics]

Example 3

\begin{tabular}{|c|c|c|}
\hline Sentence & $\begin{array}{l}\text { WSN-RFID BASED AUTONOMOUS TRANSPORT AND } \\
\text { LOGISTICS SYSTEM }\end{array}$ & Moves \\
\hline S1 & $\begin{array}{l}\text { Industrial and commercialisation of products are shifting towards } \\
\text { centralise distribution. }\end{array}$ & $\begin{array}{l}\text { MOVE 1: } \\
\text { STR }\end{array}$ \\
\hline S2 & $\begin{array}{l}\text { The idea is to serve the whole region from just one or two major } \\
\text { distribution hubs or warehouse facilities instead of national } \\
\text { stockholding operations. }\end{array}$ & $\begin{array}{l}\text { MOVE 1: } \\
\text { STR }\end{array}$ \\
\hline S3 & $\begin{array}{l}\text { Although transport logistic cost may rise but manufacturing unit costs } \\
\text { and inventory holding costs will fall. }\end{array}$ & $\begin{array}{l}\text { MOVE 1: } \\
\text { STR }\end{array}$ \\
\hline S4 & $\begin{array}{l}\text { In order to increase transport logistic efficiency, Autonomous Logistic } \\
\text { System plays a major role to ensure the efficiency of transport logistic } \\
\text { can be executed. }\end{array}$ & $\begin{array}{l}\text { MOVE 1: } \\
\text { STR }\end{array}$ \\
\hline S5 & $\begin{array}{l}\text { By utilizing RFID to detect each and every goods being loaded or } \\
\text { unloaded from the warehouse and WSN to detect the temperature for } \\
\text { perishable goods along the journey will definitely speed up } \\
\text { information processing, reduce unnecessary labour resources and } \\
\text { eliminate unnecessary waste of resources. }\end{array}$ & $\begin{array}{l}\text { MOVE 1: } \\
\text { STR }\end{array}$ \\
\hline S6 & $\begin{array}{l}\text { Furthermore with the advent of information technology which enable } \\
\text { information to be displayed on internet enable real time monitoring. }\end{array}$ & $\begin{array}{l}\text { MOVE 1: } \\
\text { STR }\end{array}$ \\
\hline
\end{tabular}

As can be seen above, the abstract which consists of six sentences has only one move which is situating the research. An abstract which contains only information on the background of the study is inadequate to facilitate the readers' in knowing the essence of the study. What readers look for in an abstract is not only the background of the study but also the research objectives, methodology and findings. These aspects of an abstract are necessary for the readers to make sense of the study without reading the whole thesis or research article. Obviously, the writer of the abstract who is a beginner writer needs to be initiated into the convention of abstract writing.

In contrast, an abstract with all the necessary five moves provides the essense of the research and hence enhances the readers' comprehension of the abstract. The abstract (see example 4) which was written by an expert writer documents the five rhetorical moves used in the abstract.

Example 4

\begin{tabular}{llc}
\hline Sentence & $\begin{array}{l}\text { A Strong User Authentification scheme with Smart Cards for Wireless } \\
\text { Communications }\end{array}$ & Moves \\
\hline S1 & $\begin{array}{l}\text { Seamless roaming over wireess network is higly desirable to mobile users and } \\
\text { security such as authentification of mobile users is challenging. }\end{array}$ & MOVE 1: \\
& STR
\end{tabular}

S2

Recently, due to tamper-resistance and convenience in manging a password

MOVE 1:

file, some smart card based secure authentification schemes have been proposed.

STR 
International Journal of Applied Linguistics \& English Literature

ISSN 2200-3592 (Print), ISSN 2200-3452 (Online)

Vol. 1 No. 7; November 2012 [Special Issue on Applied Linguistics]

MOVE 2:

PTR

MOVE 3:

DTM important security atributes sucha s preventing the various kinds of attacks, single registration, user anoymity, no password/verifier table, and high efficiency in password authentification, etc. the case that the information stored in the smart card is disclosed but the user password of the smart card owner is know to the attacker. scheme for wireless communications has been proposed to prevent from smart card breach.

MOVE 5:

DTR smart card based autentification protocils, our proposed scheme is more simple, secure and efficient.

MOVE 5:

DTR

From the example above, it is noted that the writer had commenced his abstract by providing the background information to his study (S1-S2) followed by the research objective (S3-S4). Six lines (S5-S10) were devoted to the methodology in which the writer highlighted the operation involved in the authentification protocol. From S11-S12, the writer disclosed the results of the study and then concluded with the discussion of the research Page 48 
International Journal of Applied Linguistics \& English Literature

ISSN 2200-3592 (Print), ISSN 2200-3452 (Online)

Vol. 1 No. 7; November 2012 [Special Issue on Applied Linguistics]

(S13-14). It is obvious that having such a neat sequence of rhetorical moves reflects the logical organization of the abstract which in turn provides a comprehensible overview of information to the readers (Fain, 1998).

However, based on the information gathered in Table 4 above, it is interesting to note that the majority of the expert and novice writers' abstracts had three moves. A sample of a three move abstract is shown below.

Example 5

\begin{tabular}{llc}
\hline Sentence & Text (123) & Moves \\
\hline S1 & $\begin{array}{l}\text { Knowledge Discovery in Databases (KDD) is a highly complex } \\
\text { process where a lot of data manipulation tools with different } \\
\text { characteristics have to be used together to reach the goal of }\end{array}$ & Move 1:
\end{tabular}

previously unknown, potentially useful information extraction.

S2

S3

S4

S5
The design of a KDD process implies the search for suitable tools, the understanding of their scope and proper use, their composition and so on.

All these activities can be supported by structured knowledge about the tools.

This paper is devoted to presenting KDTML, a Knowledge

Discovery Tool Markup Language for the annotation of tool characteristics, like the tool location and execution environment, I/O interface and functionalities.

As an example of use of KTDML we discuss the implementation of a wrapping service, which allows to automatically transform a KDD tool written in any imperative language into a web service.
Move 1:

STR

Move 1:

STR

Move 2:

PTR

Move 3:

DTM

STR: Situating the Research, PTR: Presenting the Research, DTR: Describing the Methodology

The abstract above was written in 135 words with five distinct sentences (S1-S5). The writer chose to commence his abstract by situating his research in which he provided some background knowledge (S1-S3) on Knowledge Discovery in Databases (KDD). He then informed the reader the purpose of the research (S4) and concluded his abstract by stating the instrument used in the study. The writer seemed not to be too concern about disclosing his findings nor discussing his research. Such a phenomenon needs further investigation as the writer did not conform to the norms of abstract writing.

\section{Conclusion}

To conclude, the findings revealed that Move 1 and Move 2 were seen to be the obligatory moves for the two groups of writers although the total occurrences of both moves were higher in the expert abstracts. Move 3 which was seen as optional for the expert writers was however, seen as obligatory for the novice writers. For Move 4, although both groups of the writers regarded the move as optional, the novice writers had less tendency of using the move than the expert writers. However, Move 5 which appeared to be optional too for both groups of writers was seen to be used more by the novice writers in the abstract writing. In other words, the expert and novice writers were seen to take Move 1 and Move 2 as the obligatory moves but for Move 3, Move 4 and Move 5 the writers tended to have different preferences of using the moves.

In terms of the move used and the comprehensibility of the abstracts, it is clear that within a five move pattern abstract, having only one move does not provide clarity of the content of the abstract. In contrast, a complete five move pattern abstracts-provides a succinct overview of the study. As stated earlier, both the expert and novice writers were seen to take Move 1 and Move 2 as obligatory moves. Therefore, it is not surprising that not all 
International Journal of Applied Linguistics \& English Literature

ISSN 2200-3592 (Print), ISSN 2200-3452 (Online)

Vol. 1 No. 7; November 2012 [Special Issue on Applied Linguistics]

abstracts were seen to utilize all the five moves.

The findings from this study have in some ways pointed to the fact that the five move pattern in abstract writing may not be the norm for abstract writing in the field of engineering. This is evident in the variation of use in the rhetorical moves in the engineering abstracts. In the pragmatic use of this genre, how an abstract is to be structured could be dictated by the publishing or academic institution. In such a case, the novice writers need to be aware of this requirement in order that they will be able to write an effective abstract.

Nevertheless, knowledge of the abstract genre is critical for novice writers. As evolving writers, knowing the structure and what it takes to write an effective abstract would ease the process of writing. Such knowledge should be imparted to the novice writers in writing classes at the tertiary level of education. It provides a platform for the novice writers to be initiated into one of the conventions of academic writing.

\section{References}

Bhatia, V. K. (1993). Analysing Genre: Language Use in Professional Settings. London: Longman.

Birch, B.S. \& Cooke. R. (2008). Help on the Spot: Online Assistance for Writing Scientific English. Professional Communication, 8 (2), 92-111.

Van Bonn, S. \& Swales, J. (2007). English and French journal abstracts in language sciences: Three exploratory studies.Journal of English for Academic Purposes, 6, 93-108.

Chakorn, O. (2002). Promotional Writing in the Thai Business Context: A Cross-Cultural Analysis of Sales

Promotional Letters. NIDA Language and Communication Journal,7, 1-26.

Fain, J.A. (1998).Writing an Abstract.The Diabetes Educators, 24 (3), 353-356.

Graetz, N. (1985). Teaching EFL students to extract structural information from abstracts. In J. M. Ulign, \& A.K. Pugh (Eds.), Reading for professional purposes: Methods and materials in teaching languages (pp. 123-135).

Hiranbuna, K. (1996). Cross-Cultural Startegies and the Use of English in International Business

Correspondence.Unpublished PhD Thesis.Flinders University of South Australia, Australia.

Holmes, R. (1997). Genre analysis, and the social sciences: an investigation of the structure of research article discussion sections in three disciplines. English for Specific Purposes, 16(4), 321-377.

Huckin, T. (2006). Abstracting from abstracts. In M. Hewings (ed.), Academic Writing in Context (pp. 93-103).

London: Continuum.

Hyland K. (2003). Genre-based pedagogies: A social response to process. Journal of Second Language

Writing, 12, 17-29.

Kanoksilapatham, B. (2007). Rhetorical Organizations of Research Article Introductions in Biochemistry and Microbiology.ESPMalaysia.A Journal on English for Specific Purposes. 13 (2), 21-37.

Mizuta, Y. \&Nigel.C. (2004). An Annotation Scheme for a Rhetorical Analysis of Biology Articles.In Proceedings of the Fourth International Conference on Language Resources and Evaluation (LREC 2004). Pho, P.D. (2008). "Research article abstracts in applied linguistics and educational technology: a study of linguistic realizations of rhetorical structure and authorial stance". Discourse Studies 10(2): 231-250.

Santos, M.B.D. (1996). The textual organization of research paper abstracts in applied linguistics. Text, 16, 481-499.

Swales, J. (1990). Genre analysis. Cambridge: Cambridge University Press

Ventola, E. (1994). Abstracts as an object of linguistic study. In S. Cmejrkova', F. Danes, \& E. Havlova' (Eds.), Writing vs. speaking: Language, text, discourse, communication. Tu“ bingen: Gunter Narr (pp. 333-352). 